\title{
Review of Debra Satz's Why some things should not be for sale. Oxford: Oxford University Press, 2010, 252 pp.
}

\author{
JOSEPH HEATH \\ University of Toronto
}

One of the major points of resistance that proponents of unrestricted markets have always encountered has been the repugnance that many people experience at the thought of certain goods and services being subject to commercial exchange. Friends of the free market have found-much to their chagrin, and occasionally, surprise-that merely pointing to the marvelous efficiency gains that can be achieved through the introduction of markets for these goods does not instantly dissolve all resistance. It is thanks to this stubborn resistance that, to this day, you cannot (in most jurisdictions) pay someone to stand in line for you, bear you a child, provide you with replacement organs, or bring you to orgasm.

On its own, this phenomenon might be regarded as little more than a curiosity, perhaps an interesting example of how cultural mores can constrain markets at the periphery. (After all, there was a time when people expressed equal abhorrence at the ignoble thought that individuals should be able to acquire land merely because they had enough money to pay for it.) The stakes were raised quite considerably, however, by Michael Walzer, who in his Spheres of justice (1983) argued that this sort of repugnance provides, not just an account of why certain markets are prohibited, but an all-purpose normative rationale for the welfare state. Specifically, he tried to show that the reason certain goods and services are provided by the public sector is precisely that it would be unethical for them to be provided by the private sector.

The first thing to be noted about Debra Satz's recent book is that, despite her many disagreements with Walzer, her work remains squarely within this tradition. Unlike theorists like Deborah Spar or Kimberly Kraweick, who are interested in "forbidden markets" as primarily local phenomena, she agrees with Walzer (and Elizabeth Anderson) that the moral intuitions at play in the domain of prostitution, reproduction, and transplantation are the same intuitions that justify the role of the public sector in the provision of health care, 
education, and old-age security. At first glance this might seem like quite a leap, so it is worth reviewing briefly what sorts of arguments are thought to be capable of carrying us across.

Walzer argued, famously, that it was a substantive feature of the goods in question that made it unethical to exchange them. Different goods belong to different socially defined "spheres", each with its own distributive logic. Thus votes are to be distributed in accordance with a principle of equal citizenship, health care in accordance with need, love in accordance with free choice, and commodities in accordance with ability to pay. Thus trying to buy votes, health care, or love, constitutes an illegitimate boundary-crossing.

There are some obvious problems with this argument, which critics were not slow to point out. The most common sort of concern, echoed by Satz (p. 81), takes as its point of departure what John Rawls referred to as the "fact of pluralism", viz. that one can expect a free society to be marked by reasonable disagreement over the values at stake in each of these spheres, as well as the appropriate principles of distribution. If, however, people assign different value to goods such as health, then it seems obvious than any principle of distribution governing such a good should be sensitive to these differences in valuation. One obvious way of satisfying this constraint is to create a market for the good, so that people can buy the amount that they want, based on their own estimation of its importance in their overall plans.

As if this were not enough, serious doubts have also been raised about the extent to which the exchange of goods is really what triggers repugnance, or whether people are merely reacting to the background inequality that underlies certain exchanges. In this respect, the work done by Alvin Roth (2007) on paired kidney exchange is extremely significant. It turns out that most people, while being offended at the thought of transplant organs being sold for cash, are not actually offended by the prospect of such organs being traded. Many people in need of a kidney transplant have family members who are willing to donate, yet cannot because of incompatibility. Consider the case of two patients in such a situation, each of whom has an incompatible donor, but each of whom is also compatible with the other's donor. Would there being anything wrong with bringing the four of them together, in effect, swapping kidneys between the two donors? There tends not to be a strong reaction against this arrangement. 
But if two people can swap donors, it does not seem unreasonable that three people should be able to do so, or that four should be able to do so, or that arbitrarily long chains of paired donors should be arranged. The end result is the creation of a barter economy for transplant organs, something that, again, most people find unobjectionable. ${ }^{1}$ After all, it produces significant efficiency gains (which, in this case, mean many lives saved).

What is the difference between an ordinary market and this barter system? The only morally salient difference seems to be that, in the kidney exchange system, endowments are necessarily equalized, since the only thing you can use to "buy" a kidney is another kidney. The problem with being able to use cash to pay for a transplant, rather than another donated kidney, is that it allows people to take potentially undeserved advantages they have acquired in other domains of social exchange (e.g., inherited wealth, citizenship in a first-world country, and so on), and transfer it over into the domain of kidney acquisition. Thus the prohibition on markets for kidneys starts to look like an egalitarian intuition, not one having to do with the sacredness of the human body or anything like that.

To admit this, however, is to risk undermining the idea that there should be any prohibited markets. This is because (as Satz rightly observes) there is a familiar line of reasoning in welfare economics which shows that, if inequality is the problem, then the best way to address it is by making adjustments on the income side, not by interfering with particular markets. Why? Because this both permits a more effective solution to the inequality problem and allows participants to realize the efficiency gains associated with market exchange. As Abba Lerner put it: "If a redistribution of income is desired it is best brought about by a direct transfer of money income. The sacrifice of the optimum allocation of goods is not economically necessary" (Lerner 1970, 48).

Because of this, there is a very slippery slope that leads from Walzer's position directly to a view that Satz, following James Tobin, refers to as "general egalitarianism", which justifies no restrictions in principle on the scope of market exchange. To the extent that a case can be made for restricting a particular market, it will be due to 1) efficiency

\footnotetext{
${ }^{1}$ Some may regard this as permissible because it is an extended system of gift exchange. But this is a reduction of the communitarian intuition. If it were true, then the market itself would be nothing but a gigantic system of gift exchange.
} 
concerns arising from market imperfections (externalities, asymmetric information, market power, and so forth), or, 2) paternalistic concern that improving the distribution of income will not result in the right sort of improvements in final outcome. (The latter sort of rationale is, of course, dubious given the "fact of pluralism".) If a market raises neither of these two concerns, then the general egalitarian would regard any repugnance we may experience as nothing but a "yuck" response, which we must learn to overcome.

The best way of describing Satz's position would be to say that she wants to embrace a fully liberal perspective, while nevertheless stopping somewhere short of general egalitarianism. Thus she accepts that, to the extent that markets are prohibited, it will be on the basis of general principles, not on the basis of anything specific to the particular good being exchanged. ${ }^{2}$ She also seems to want the principles that do the prohibiting to satisfy a neutrality constraint. By contrast to the general egalitarian, however, she wants to offer a broader interpretation of the considerations that could justify prohibition of a market. For starters, she provides what could best be described as a generous interpretation of the egalitarian and efficiency principles. Thus she identifies four characteristics that make a market "noxious": that it produces harmful outcomes for individuals, or for social relations, or that it involves highly asymmetric information or agency, or that one of the parties exhibits extreme vulnerability.

Going through the examples she provides, however, one gets the sense that all of them could be construed as problematic from the general egalitarian view as well: "markets whose products are based on deception, even when there is no serious harm" (p. 97), (asymmetric information); "markets in urgently needed goods where there is only a small set of suppliers" (p. 97), (market power). Furthermore, the example that she gives of a market that should be restricted for egalitarian reasons, viz. "a grain market whose operation leaves some people starving because they cannot afford the price" (p. 94), is one that seems more appropriately handled by the general egalitarian remedy of income redistribution.

Of course, while the general egalitarian might be able to accommodate these concerns, Satz is certainly correct in pointing out that the standard version of this position interprets both the efficiency

\footnotetext{
2 Thus Satz grants that "perhaps many of our reactions are little more than an irrational repugnance at that which we dislike" (p. 112).
} 
and the equality principle quite narrowly. For example, she observes (quite astutely) that an enormous amount of normative work gets done by what economists are willing to classify as an externality (p. 32). Typically the set of externalities is limited to what John Stuart Mill would classify as "harms", even though this is in no way entailed by a general welfarist framework. If one looks further, one can see all sorts of cultural and social consequences of market interactions that are simply ignored in standard economic analysis. ${ }^{3}$ For example, Satz notes that in jurisdictions where kidney-selling is legal, kidneys are increasingly used (and demanded) as collateral for loans. This is obviously an untoward effect, but one that is difficult to classify using the traditional categories of external effect.

With respect to equality, Satz also wants to expand the traditional understanding to include more than just unequal endowments and asymmetric bargaining power. She argues that the operations of particular markets may "undermine the conditions that people need if they are to relate as equals" (p. 94), and undermine the ability of some to "participate competently and meaningfully in democratic self-governance" (p. 101). ${ }^{4}$ This cannot be remedied through income redistribution, in her view, but requires that some exchanges be prohibited, and that other types of goods be provided by the welfarestate in-kind (p. 102).

Satz spends a fair bit of time defending her view on equality (essentially a type of non-responsibility sensitive egalitarianism with a "basic needs" flavor), something that strikes me as being a slight misdirection of effort, since there is very little in her view of equality per se that distinguishes her position from that of the general egalitarian. In particular, it is far too easy to assume that, because the state has an obligation to ensure that the basic needs of all citizens are met, that the state must do more than just redistribute income. Why should that be? If people have sufficient income, and if their basic needs are indeed basic, then why would they not go out and purchase everything that they require to satisfy these needs on the market? The idea that guaranteeing minimal income is somehow different from

\footnotetext{
${ }^{3}$ The exception to this is Fred Hirsch, who made a number of suggestive observations about the cultural consequences of commodification, particularly with respect to the way that charging for a good can change its social meaning (Hirsch 1978, 84-101). These observations, however, have not received much uptake.

${ }^{4}$ There are interesting parallels between this view and the one developed by Kevin Olson (2006, 15-18).
} 
guaranteeing basic needs presupposes a seemingly paternalistic concern, i.e., that people will not actually spend their money satisfying their supposedly basic needs.

Thus the most important difference between Satz's view and the general egalitarian's stems from the way that she justifies these restrictions (or "blockages") on individual choice. "The basis of this blockage is not paternalistic", she argues, "it is focused on a view about the source of the donor's obligations, not on a view about what is in the recipient's best interest" (p. 79). In other words, she claims, the state must provide for certain needs in-kind, without any opt-out, because it is under an obligation to achieve a certain sort of outcome, regardless of whether the individuals in question happen to value that outcome.

This seems fine, as far is it goes. Unfortunately, she says little about where this obligation comes from, or more importantly, how one could justify an obligation on the part of the state to ensure that a particular person's basic needs were satisfied without making any reference to what is good for that person, and without presupposing some sort of perfectionism. One would like to have seen more development of this point, since it seems like the one issue on which there really is a significant disagreement between Satz and the general egalitarian.

After outlining her basic normative framework, Satz moves on in the second half of the book to present a series of applications of this framework to particular issues that have generated philosophical discussion. (It is noteworthy that these are all questions about "forbidden markets", such as prostitution, organ donation, child labor, and so on, not welfare-state staples like education and health care.) There is plenty of common sense on display throughout. Furthermore, because she does not think that any of these exchanges are intrinsically wrong, Satz exhibits admirable receptivity to the range of empirical evidence that is relevant to the assessment of these markets.

There is a fair amount of pointed criticism of opposing views in these sections. For example, Satz repeatedly makes the observation that in order to justify prohibition of a particular exchange, it is not adequate simply to come up with a reason why it should be banned. One must also show that this would not result in the prohibition of all sorts of other markets that no one has any particular problem with. (In other words, one must worry not just about the confirming inference, but also about the disconfirming contrapositive.) This may seem like a simple point of logic, but she uses it to cut an 
extraordinarily wide swath through the philosophical literature, often with a measure of subtle wit. For example, she dismisses the argument that prostitution is an exchange that women enter into only out of "desperation" on the grounds that "there is no strong evidence that prostitution is, at least in the United States and certainly among its higher echelons, a more desperate exchange than, say, working in Walmart" (p. 141).

However, having praised Satz's receptivity to empirical considerations, there is one small complaint that I would like to register. At two rather key points in the argument, Satz appeals to what she, following Jonathan Wolff, calls the "Titanic puzzle". This puzzle arises from a rather throw-away line in Thomas Schelling's Choice and consequence, in which he suggested that the Titanic had an inadequate number of lifeboats because passengers in 3rd class (or "steerage") were expected to "go down with the ship" (Schelling 1984, 115), and that this was somehow part of the conditions of carriage associated with the less expensive tickets. The puzzle is then as follows: assuming that we find it outrageous for passengers on the same ship to have differential access to lifeboats, on the grounds that some did and some did not pay for this safety feature, how then can we accept an arrangement under which passengers on different ships, having paid different prices for carriage, have access to different levels of safety?

The puzzle is fine so long as one is simply looking for an intuitionpump. It is important to realize, however, that this account of conditions on the Titanic is entirely fictitious (indeed, the suggestion that there was a policy of denying 3rd class passengers access to the lifeboats was vehemently denied by White Star Lines). Differential rates of survival among Titanic passengers were very much a product of early 20th-century social mores, not ex ante contracting. First priority was given to women and children, and after that, male passengers (on one side of the ship men were barred entirely from entering the lifeboats). This was reflected in the fact that survival rates among female 3rd class passengers was higher than among any group of male passengers, including those in 1st class. Indeed, much of the discrepancy in survival rates between 1st, 2nd, and 3rd class passengers was due to the lower proportion of women in steerage, along with the physical positioning of the lifeboats on the upper decks (Butler 1998, 105-106).

I am drawing attention to these facts not just in the hope of preventing an urban myth from taking hold in the philosophical 
literature, but also to make a point that is relevant to the normative assessment of the thought-experiment. Satz claims that in the Schelling scenario, the selling of tickets with differential access to lifeboats is impermissible because it undermines the conditions of equal status among passengers, by treating the lives of some as worth more than those of others. Yet the fact that we routinely pass over in silence arrangements in which men are exposed to much greater risk than women suggests that there is no general norm requiring equal safety in our society.

This has broad ramifications in many areas of economic life. In the typical wealthy country physically dangerous work is done almost entirely by men. In Canada, for instance, in 2005, over 97\% of workplace fatalities were among men-in numbers, out of 1097 deaths, 1069 were of men, 28 of women (Sharpe and Hardt 2006, 25-26). Yet instead of being met with outrage, the standard response to this statistic is to say "well, they get paid more to do this sort of work". This is, of course, precisely the response that we find unacceptable in the fictitious Titanic scenario.

What this suggests, in my view, is that there is no general norm of equality underlying our response to the Titanic case, because we do not actually believe that equal safety is required for equality of status. One possibility is that the situation of a sinking ship evokes a particular set of social norms, similar to those governing what G. A. Cohen described as "the camping trip" (2009). A more likely explanation is simply that we find male victims of class discrimination more sympathetic than male victims of sex discrimination. If this is true-and if we are not committed to any general principle of equal safety-then by Satz's argument our reaction to the fictitious Titanic scenario may just be a type of repugnance that we need to get over.

\section{REFERENCES}

Butler, Robert Allen. 1998. Unsinkable. New York: Stackpole Books.

Cohen, Gerald Allan. 2009. Why not socialism? Princeton: Princeton University Press.

Hirsch, Fred. 1978. The social limits to growth. Cambridge (MA): Harvard University Press.

Lerner, Abba. 1970. The economics of control. New York: A. M. Kelley.

Olson, Kevin. 2006. Reflexive democracy. Cambridge (MA): MIT Press.

Roth, Alvin E. 2007. Repugnance as a constraint on markets. Journal of Economic Perspectives, 21 (3): 37-58.

Schelling, Thomas. 1984. Choice and consequence. Cambridge (MA): Harvard University Press. 
Sharpe, Andrew, and Jill Hardt. 2006. Five deaths a day: workplace fatalities in Canada, 1993-2005. CSLS Research Paper 2006-04. Centre for the Study of Living Standards, Ottawa, Canada. http://www.csls.ca/reports/csls2006-04.pdf (accessed May 2011).

Walzer, Michael. 1983. Spheres of justice. New York: Basic Books.

Joseph Heath is professor in the department of philosophy at the University of Toronto. He is the author of several books, including Communicative action and rational choice (MIT Press, 2001) and Following the rules (Oxford University Press, 2008).

Contact e-mail: <joseph.heath@utoronto.ca> 